\title{
Client preferences in counselling for alcohol problems: a qualitative investigation
}

Jillian Walls

Julia McLeod

John McLeod

This is the peer reviewed version of the following article:

Walls, J., McLeod, J. and McLeod, J. (2016) 'Client preferences in counselling for alcohol problems: a qualitative investigation'. Counselling \& Psychotherapy Research, 16(2): pp.109-118.

It has been published in final form at DOI:

https://doi.org/10.1002/capr.12064

This article may be used for non-commercial purposes in accordance with Wiley Terms and Conditions for Self-Archiving 
Pre-publication copy of:

Walls, J., McLeod, J., \& McLeod, J. (2016). Client preferences in counselling for alcohol problems: A qualitative investigation. Counselling and Psychotherapy Research, 16(2), 109-118. https://doi.org/10.1002/capr.12064

Client preferences in counselling for alcohol problems: a qualitative investigation

Jillian Walls (1)

Julia McLeod (2)

John McLeod (3)

(1) Tayside Council on Alcohol, Dundee

(2) Division of Mental Health Nursing and Counselling, University of Abertay

(3) Department of Psychology, University of Oslo 


\begin{abstract}
Background: Incorporating client expectations and preferences into the counselling process can lead to more positive outcomes and lower rates of drop-out. Aim: The aim of this study was to explore preferences for counselling held by clients prior to the commencement of counselling Method: Semi-structured interviews were conducted with five clients seeking help from an alcohol counselling service, and analysed using Interpretative Phenomenological Analysis. Findings: Each client described a distinctive individual preference profile. While holding clear preferences for what would be helpful in counselling, clients were also open to new possibilities. They possessed a personal understanding of why certain activities and types of relationship might be helpful for them, and an appreciation of the types of therapeutic process that might lead them to quit therapy. Conclusions. These findings suggest that clients are able to articulate their preferences, when offered the opportunity, and that qualitative methods have the potential to open up new understanding of the structure and meaning of preferences from the point of view of the client.
\end{abstract}

Keywords

alcohol misuse; client experience; helpfulness; preferences; qualitative research 
Title: Client preferences in counselling for alcohol problems: a qualitative investigation

\section{Introduction}

The ideas held by clients about what may happen in therapy, and the links between these ideas the process and outcome of therapy, have been extensively studied within the therapy research literature. This topic has been explored using a range of constructs: beliefs, attitudes, expectations, choice, credibility of treatment models, insider knowledge, theory of change, theory of cure, multiple intelligence, learning style, hope (McLeod, 2015). In recent years, the concept of preference has emerged as a particularly significant focus of attraction in this area of inquiry. Client preferences represent the strategies and activities that clients wish to pursue in therapy. As a result, information about preferences possesses substantial implications for practice.

On the whole, clients report more positive outcomes from counselling and are significantly less likely to drop out of therapy when their preferences are met (Lindhiem, Bennett, Trentacosta, \& McLear, 2014; McLeod, 2012, 2013; Swift \& Callahan, 2009). For example, Berg, Sandahl \& Clinton (2008) found that clients who had no previous experience of therapy, and invited to indicate their preferences prior to the start of treatment, recorded a higher level of symptom reduction when they received therapy in which preferred therapeutic activities were present. Outcomes of therapy are also influenced by the extent to which client pre-therapy preferences are fulfilled in respect of therapist attributes such as age, gender and ethnicity (Chan \& Quinn, 2009; Furnham \& Swami, 2008), and therapist relationship style (Bowman \& Fine, 2000; Dremen, 1977; Swift \& Callahan, 2010). However, in some studies, receiving a preferred form of therapy has been found to make no difference to client satisfaction or outcome (Lindhiem, et al., 2014; Swift \& Callahan, 2009). Brief pre-therapy preference measures (Bowens \& Cooper, 2012), and interview schedules Vollmer, Grote, Lange, \& Walker, 2009) have been designed to facilitate the tailoring of therapy to the preferences of individual clients.

The relationship between preference and outcome appears to be attributable to two main factors. Higher levels of client control over the process of counselling may lead to a more positive engagement in the process of therapy (Handelzalts \& Keinan, 2010). In addition, therapist attention to the ideas of the client about what will be helpful, contributes to the strength of the therapeutic alliance (Vollmer, Grote, Lange, \& Walker, 2009).

The importance of client preferences has been widely acknowledged in the field of alcohol counseling (Beckman, 1994; Humphreys \& Tucker, 2002). The acknowledgement that "one size fits all" does not apply to people struggling to overcome problems in alcohol use, was reflected in the widely-applied "stages of change" model (Norcross, Krebs, \& Prochaska, 2011; Prochaska, \& DiClemente, 1986), and in Project Match, a major controlled outcome study that investigated the relative effectiveness of different interventions with different types of client (Project MATCH Research Group, 1997). However, these initiatives relied on expert-driven assessments of client differential responsiveness, rather than on directly asking clients about their preferences. More recently, responsiveness to client-defined preferences around treatment goals have been found to predict outcome (Adamson, Heather, Morton, \& and Raistrick, 2010), while Andréasson, Danielsson, \& Wallhed-Finn, 2013). have documented the existence of wide differences between clients with alcohol problems in respect of the form of therapy that they believe would be most effective for them

The consistent finding that attention to client preferences reduces attrition from therapy has implications for counselling with individuals experiencing alcohol and drug addiction. High levels of early drop-out from treatment are typical in such settings (Baekeland \& Lundwall, 1975). For example, in a study of a specialist alcohol treatment clinic in the U.K., Jackson et al. (2006) found that only $42 \%$ of clients attended for more than one session. It is possible that a more individually-tailored approach to therapy, informed by a commitment to 
take explicit account of client preferences, could reduce do not attend (DNA) rates in such services.

There is an absence of qualitative research into the meaning of preferences from the point of view of the client. It is likely that such knowledge has the potential to contribute to the development of theory and practice around this topic. The aim of the present study was to explore the views of service users in an alcohol counselling agency, regarding their preferences around different aspects of counselling, and their perception of the role of preference matching in allowing them to remain in treatment.

\section{Method}

The study was carried out in accordance with the procedures of Interpretative Phenomenological Analysis (IPA; Smith, Flowers \& Larkin, 2009), an approach to qualitative inquiry that provides a structure for intensive analysis of the personal meaning of areas of social life. IPA advocates case-by-case interpretation of interview material collected from a limited sample of informants, in order to construct an interpretative framework that reflects the diversity of experience reported by those taking part in the study.

\section{Participants}

The participants in this study were recruited from Tayside Council on Alcohol (TCA), an urbanbased counselling agency that specialises in alcohol and drug support work with adults, young people, and children. Clients can self-referred, or are referred by GPs, social workers or the court system. The extent of the DNA issue in XCA is reflected in statistics collected during 2013: 786 clients were referred to the service; 261 did not attend any appointments at all, a further 89 dropped out after an initial screening appointment, and an additional 176 dropped out after a single counselling session. Only 260 clients (32\% of referrals) reported a meaningful level of engagement in counselling.

For the purposes of the present study, 25 consecutive clients referred to TCA during a specified period of time were invited to take part in the research, through a letter and information sheet that described the project as an investigation of "what clients want from counselling". The only criteria they had to meet was that they had been offered an assessment interview but had not have yet met with a counsellor from XCA during their current helpseeking episode. The only five clients to accept this invitation were recruited into the study: 3 men and 2 women, ranging in age from early 30s to late 50s (Table 1). The target sample size of 5 is typical of IPA methodology (Brocki, \& Wearden, 2006), which aims to identify differences between individual informants, as well as shared themes. Of the 20 clients who did not agree to be interviewed, 8 did not accept the invitation to attend for assessment, while 7 replied that they could not afford the time to be interviewed. Reasons for non-compliance for the remaining 5 individuals are not known.

[Insert Table 1 about here]

\section{Data collection}

Interviews took place on the XCA premises, lasted between 30 - 60 minutes and were audio recorded. A semi-structured interview schedule was developed, which used open-ended questions around beliefs and preferences in areas such as what the individual wanted to gain from counselling, how they felt counselling could help, their role as a client, and the role and characteristics of the counsellor. Towards the latter half of the interview, participants were invited to read and comment on the Therapy Personalisation Form (Bowens \& Cooper, 2012), an instrument that was has been used as a tool to encourage collaboration between the 
counsellor and client on different aspects of client preferences. The form includes 20 items, and asks clients to use an 11-point scale to indicate a preference for how they wish the counsellor to work with them, along such dimensions as "using lots of techniques and exercises" or "allowing me to take a lead in therapy". For the purposes of the present study, participants were not asked to complete the form but were asked to read it and comment on whether any of the preferences mentioned on the form were important to them, and why. In the final stage of the interview, the interviewer described the key features of cognitive-behavioural, psychodynamic and person-centred approaches to counselling, and invited participants to comment on their preferences in respect of these models. At the end of their interview, participants were asked about their experience of taking part in the research.

Data analysis

Interviews were recorded and transcribed and subjected to Interpretative Phenomenological Analysis (IPA; Smith, Flowers \& Larkin, 2009). The process of analysis began with the primary researcher listening repeatedly to the interviews as well as continually reading the transcripts in order to become immersed in the data. After the researcher had become familiar with the data, each transcript was then analysed separately, in accordance with IPA principles, based on sequential reading of the text, initially for constituent elements of meaning and then later for interpretive themes. Further data analysis occurred in the context of monthly meetings with a research group, and additional one-to-one meetings with a research colleague, at which primary meaning codes were compared, and emerging themes were discussed. The final set of themes was audited by an experienced researcher, who examined samples of the data and compared his analysis of the material with themes identified by members of the group. Differences in data interpretation were resolved through discussion. It proved to be relatively straightforward to identify specific client preferences. However, preference themes were highly interlinked and implicit, and harder to differentiate. Discussion within the research team did not centre on fundamental differences in data interpretation, but instead were concerned with ways of representing meaning and labaleling themes.

\section{Ethical procedures}

Participants were asked to read an information sheet and sign a consent form. Ethical approval for the study was granted by the Research Ethics Committee, School of Social and Health Sciences, University of Abertay Dundee and by TCA.

\section{Researcher reflexivity}

As a counsellor in TCA, the primary researcher was aware of the high drop-our rate in the agency and wanted to learn how to engage clients in counselling in order to achieve better outcomes. The primary researcher kept a reflective journal in order to record and reflect on her experience of conducting the study. Material from the journal was discussed with colleagues and research supervisors. This procedure was used to nebale the interviewer to "bracket-off" her pre-understandings and remain as open as possible to the meanings being expressed by participants (Fischer, 2009). The co-authors of the paper were experienced counselling trainers and researchers, with no prior experience of working in the field of alcohol counselling. Before commencing the study, all three authors believed that client preferences were important, but had no specific expectations around what the interviews might produce. All of us were surprised about the strength and clarity of client preferences uncovered in the course of the study, and the importance of negative preferences. .

\section{Results}


Findings are first presented in terms of patterns of specific therapy preferences associated with each client. This is followed by an account of the main overarching themes that emerged from analysis of the transcript data.

\section{Patterns of preference}

The clients in this study expressed a broadly equal proportion of positive preferences (what I believe will be helpful for me in therapy) and negative preferences (what might make me walk away from therapy). The specific preferences identified by each participant, based on open interview data as well as reactions to the Therapy Preference Form, are summarized in Table 2. Across individual participants, there were preference differences that would have major implications for the type of therapeutic intervention that would be regarded as acceptable. Participants 2, 3 and 5 were keen on homework tasks, whereas participants 1 and 4 were against homework due to other commitments and time limitations. Two participants spoke of "tough love", a term that had not been used by the interviewer. However, one was all for "tough love" in that she appreciated the challenges that would come from counseling, whereas the other participant spoke of "tough love" in a negative sense. Although this client saw herself as being open to challenge, she felt tough love was the opposite of what she needed, which was "support". Participant 1 felt that in order to talk and share his story he would benefit from the counsellor asking questions, whereas Participant 2 described a negative experience with help in the past where she had been asked questions which had prevented her from opening up.

[Insert Table 2 about here]

Preference themes

Running through the specific preferences that were mentioned by participants, it was possible to identify a set of underlying themes: I am open to new possibilities; I have a sense of the type of relationship that will be most helpful for me; I understand why some things are helpful for me and others are not; I need to be honest. These themes do not refer to specific preferences expressed by clients, but instead represent the interpretative context within which these specific preferences were embedded and can be regarded as "meta-preferences": overarching principles that organize client preference positions.

\section{I am open to new possibilities}

It became apparent throughout the interviews that while all of these clients expressed a wide range of specific preferences, they also described themselves as open to new possibilities. For example, Participant 5 stated that "at this stage I'm open to everything...I have no limitations". This sense of uncertainty and open-ness was also apparent when some participants responded to the descriptions of therapy approaches offered by the interviewer. After providing a description on various approaches Participant 2 observed that "they all sound like they would be very helpful actually". Earlier in her interview, Participant 3 had described a general preference for a problem-solving approach to therapy. However, when offered a brief description of psychodynamic counselling, she stated that:

I mean I know I said I want to tackle the underlying issue but yeah I quite like the sound of the last one and psychodynamic because I didn't have the best of childhoods as well (Participant 3). 
The position of open-ness reflected in these statements appeared to refer to an underlying expectation that the counsellor would take an active role in offering new ideas, perspectives and techniques, and that they would welcome such suggestions.

\section{I have a sense of the type of relationship that will be most helpful for me}

Participants talked at length about the counsellor qualities, and type of relationship, that they believed would be most helpful for them, or would lead them quitting therapy. Although each of them expressed a somewhat different image of their preferred or "ideal" therapist, all of them appeared to believe that being offered the type of relationship that was most suitable for them, would be a key factor contributing to the eventual success of therapy they received.

Participants found it hard to be explicit about the relationship qualities that would be most relevant to them. Instead, they seemed to posses an implicit sense of what would work for them, and what would not. In interviews, participants took the opportunity to rehearse and explore their implicit sense of what they were looking for in a therapy relationship. For example, several participants talked about the complex issues associated with the desirability of having a counsellor who had experience of a problem with alcohol from which they had recovered. Some believed that although such experience could add something to the counsellor's understanding of what they as clients were going through:

....people that haven't had the experience can't truly understand what it's like. (Participant 3)

However, having experience of overcoming a problem could also be a hindrance:

I feel that a lot of people that have had an addiction that go into alcohol counselling they might advocate a certain method, so if AA has worked for them, they might steer you to that route, they might not but they'll give, they might not mean to but I think they are more likely to suggest a particular route when actually that might not be the right route for you mm so its got its pros and cons (Participant 3)

In assessing the quality of the therapy relationship, all participants in the study reported that they were looking for someone with whom they could share their story. Individual participants held different ideas around what this would involve. For some, telling the story could be could be facilitated by asking questions: "it would make it more easier to talk basically and to get stuff out especially if they're asking you questions you'll be able to answer them a lot easier." (P1). Other participants were looking for a counsellor who would not only listen and help them to tell their story, but also challenge them by pointing out discrepancies in what they said:

...perhaps point out where there may be gaps and holes in my logic, or whether I'm being contradictory (P5)

There was a general sense among participants that their counsellor should help them to identify and work toward mutually agreed future goals. One participant referred to his previous experience in a form of counselling in which there was a lack of clarity around goals:

I didn't have a particularly clear idea of what I was looking for or what we were doing .... it kind of felt that I was pulling things out the air, rather than focusing on specifics. (P5).

All of the participants in this study expressed a preference for a therapy process characterised by collaborative decision-making.

Although there was a lack of clarity around what a positive collaborative process might look like, there was a much stronger sense of what it might feel like if this process went wrong. Although these clients were open to new possibilities, this came with a ground rule that they 
do not want to be directed down a route with which they were not comfortable. Participant 1 stated that he would be likely to withdraw from therapy "if they [the counsellor] judged you or if you felt backed into a corner (P1). This concept of being "backed into a corner" came through in all the interviews, in the form of a worry that what they were saying would be ignored by the counsellor, or that their counsellor would pursue their own personal agenda. Within this domain, participants appeared to be expressing a strong negative preference, in relation to relationship qualities that would result in them leaving therapy.

\section{I understand why some things are helpful for me, and other things are not}

Each of the clients in this study had struggled for many years to overcome serious problems around alcohol use. Through this experience, each individual had developed his or her own personal understanding of the underlying cause of their problem, and what they needed to do now, at this point in their recovery. When a participant stated a preference, they could usually offer a story that explained why they had this preference.

An important factor that shaped participants preferences was their past experience with help. A negative experience in a previous helping relationship would lead to knowledge of what was not wanted in their forthcoming counseling episode:

They were clueless, like, you know. I go in there, a hardened drinker and the guy that was interviewing us goes right he says 'I don't want you to have a drink for at least three to six months' and... I mean, how ludicrous is that, its like telling a fish no to swim or a bird no to fly. I'm an alcoholic you know? (P4)

By contrast, Participant 5 had attended counselling on three separate occasions in the past and reflected upon it as being "super productive". Therefore his preferences for counselling were formed from a positive counselling experience. Participant 4 explained how he had been helped by drama therapy, and would be interested in the possibility of a similar experience in the future: "I found it fascinating because it was something totally different, something I'd never done before."

All of the participants in the study recognised that there needed to be a change in their behavior around using alcohol. Their ideas about how this would happen were based on reflection on previous experience. P1 had reached a point where he acknowledged that a controlled drinking goal had not worked for him in the past::

In the past I tried to cut back on my drinking but that never really helped whereas now I kind of realise that its maybe better that I stop drinking rather than trying to cut back because I just can't do it

By contrast, P2 had developed an understanding of how she used alcohol as a form of emotional self-regulation, and wished to pursue this insight further:

I hope to really get an idea about why I'm trying to numb my pain, what it is that is making me just go home and sit and drink alcohol rather than go on and get up and live.

A final subordinate theme within the broad area of understanding why some things are helpful and others are not was related to the way in which the participants understood and defined their sense of personal identity.. Several participants described themselves as having difficulties in talking with people around them, leading to a preference for a counsellor who would help them to talk: "like I say, I'm not the best of talkers so I don't really tell my problems to anyone close or that" (P1). A number of the participants spoke about being someone who "bottles things up" and "had trust issues" (P3) or putting up "barriers" (P2) and were looking for a form of counselling that could help them to tell their story. Participant 4 
did feel that he would want a female counsellor because of his male identity: "I find women easier to talk to, because when your with a man, its all macho, 'oh yes I'm alright no' .... I just find women easier to speak to" (P4). These examples demonstrate that, as well as being able to explain their preferences in terms of previous experiences of therapy, participants also accounted for their preferences in terms of their understanding of who they were as people their general personality (someone who "bottles things up") and sense of identity (for example: gender identity as a "macho" male).

\section{I need to be honest}

A final theme, which was apparent in the interviews conducted with all participants in the study, referred to a preference for self-in-therapy. Therapy could only be helpful if they were willing to take it seriously: "the only thing that would make me drop out is if I wasn't serious about actually doing therapy". (P1). One participant explained that previous episodes of counselling had been undermined by his lack of personal commitment to the change process: "when I first went to counselling it was to placate others more than myself. That has drastically changed now... " (P5). Participants believed that they had a responsibility to be honest with the counsellor if they expected the counsellor to be able to help them in any way: "...there is no point coming here to tell lies, or not telling lies but no telling the whole story. You can't help me if I didn't tell you everything" (P4)

\section{The experience of taking part in the research}

All participants appeared to be fully engaged in the interview process. Comments at the end of the interview included "really interesting experience" (P2) and "its raised loads of things I would never have thought of

\section{Discussion}

This study explored client preferences and expectations within an alcohol agency setting, by asking clients, before they commenced therapy, to identify the type of counselling experience that they believed would be most helpful to them. The key findings of the study were: participants expressed different preference profiles; their ideas about what would be helpful were based in considerable personal reflection on the nature and personal meaning of their troubles, as well as on previous experiences of receiving help; clients expressed negative preferences in relation to therapy processes that might lead them to terminate treatment. This qualitative interview-based study confirms conclusions drawn from analyses of responses to preference questionnaire measures (Lindhiem et al., 2014; Swift and Callahan, 2009, 2010), that there exist important differences between clients in terms of their preferences for specific therapy activities and therapeutic relationship, as well as introducing some new perspectives.

In addition to preferences for specific therapy activities and therapist qualities, clients were open to new possibilities within counselling, and viewed their therapist as a source of potentially valuable new ideas. Participants in the present study expressed an interest in learning more about their options in therapy. This finding complements the results of previous research on providing information to clients (Bowman \& Fine, 2000; Handelzalts and Keinan, 2010; Snape, Perren, Jones, \& Rowland, 2003) and supports the use of preference feedback tools in therapy (Bowens and Cooper, 2012) and preference interviews (Vollmer, Grote, Lange, \& Walker, 2009) that introduce such options.

Clients expressed preferences around the type of therapeutic relationship that would be best for them. Similar to previous research (Bowman \& Fine, 2000; Westra, Aviram, Barnes \& Angus, 2010), key positive therapist attributes, for these participants, centred on a 
willingness to be actively involved, open to collaboration, and work toward mutually agreed goals. However, participants also identified a strong negative relational preference, in the form of not wanting to feel "backed into a corner"..While there appeared to be a certain degree of open-ness and fluidity around how important it would be for the therapy process and relationship to match their positively-framed preferences, it appeared that therapy that matched their negative preferences would be likely to bring therapy to an end, no matter how many other productive processes were being experienced. To the best of our knowledge, the phenomenon of negative preferences has not been identified in previous research. This preference dimension has potentially significant implications around the development of strategies for reducing levels of early termination of treatment

The clients interviewed in this study expressed preferences for their own actions in therapy, reinforcing the observations of Patterson, Uhlin \& Anderson (2008) that when a client believes that they are responsible for the outcomes of counselling, they are more likely to form a strong relationship with their counsellor which in turn can lead to better therapeutic outcomes. It is possible that preferences around personal honesty and commitment may function as important mediators in respect of preferences for therapist characteristics and therapeutic activities. It is not merely that clients believe that certain types of therapeutic activity will be helpful for them; they also need to be courageous enough to take advantages of these preferred opportunities (Manthei, 2007).

Clients were able to provide a rationale for their preferences, in terms of previous therapeutic experiences, personal reflection on their struggle with alcohol misuse, and how they saw themselves to be in terms of personality traits and identity. This finding suggests that active therapist exploration of client preferences may have therapeutic benefit in its own right, as a means of opening up important areas of self-experience. It would be valuable, in future research, to analyse the types of conversations that take place following client completion of preference-oriented feedback measures.

\section{Limitations of the study}

It is important to proceed with caution in relation to any attempt to generalise from the findings of the present study. The research was carried out with a small number of participants and in a specialised field of counselling. Many clients declined the opportunity to take part in the study - it is possible that the sample consisted of individuals who are more thoughtful or reflective around the therapy process, compared to other clients who made use of this counselling service. It is likely that individuals with longstanding issues around alcohol will have received help from a variety of sources, and as a result may have developed a capacity to differentiate between more-helpful and less-helpful interventions. In addition, the researcher was employed by the counselling agency, which may have impacted upon how participants discussed the topic. However, research participants appeared to be fully involved in the interviews, and were willing to talk openly about their experiences and hopes around therapy. In the context of previous research into counselling for alcohol problems, it would be valuable to explore the extent to which preferences relate to the stage of change of the client, and the ways in which preferences altered over the course of therapy as the client proceeded through these stages. The findings of the study identified a possible tension between client preferences and open-ness to new ideas that might be provided by their therapist. It would be valuable, in future research, to track the ways in which therapy outcomes reflect both collaborative work around preferred activities, and the adoption by the client of new perspectives and problem-solving strategies. An important aspect of the present study was the extent to which the ideas of clients about what they needed in therapy, were shaped by personal experience of the specific problem with which they were struggling. It may therefore be useful, in future research into client preferences for therapy activities and 
relationships, to take account of distinctive, problem-related client knowledge, as well as more generic preference dimensions.

Implications for practice

Previous research has demonstrated that the therapeutic relationship and client outcomes are enhanced when therapy is informed by client preferences. The findings of this study extend these practical implications in a number of ways. Pre-therapy conversations around preferences appeared to enable clients to access their own knowledge about their problems, in ways that might provide a valuable starting-point for subsequent therapy. Clients were particularly aware of therapist attitudes and activities that might make want them to quit therapy. This kind of information could be invaluable in the early stages of therapy, when client commitment to treatment is still fragile. Finally, clients seemed to be looking for a relationship in which their counsellor was responsive to their preferences while at the same time being willing to introduce the client to new ideas and strategies.

\section{References}

Adamson, S.J., Heather, N., Morton, V., \& Raistrick, D. (2010). Initial preference for drinking goal in the treatment of alcohol problems: II. Treatment outcomes. Alcohol \& Alcoholism, 45, 136-142, DOI: 10.1093/alcalc/agq005

Andr005agq, S., Danielsson, A.-K., \& and Wallhed-Finn, S. (2013). Preferences regarding treatment for alcohol problems. Alcohol \& Alcoholism, 48, 694holism, 4: 10.1093/alcalc/agt067

Beckman, L.J. (1994). Treatment needs of women with alcohol problems. Alcohol, Health and Research World, 18, 206-211.

Berg, A.L., Sandahl, C., \& Clinton, D. (2008). The relationship of treatment preferences and experiences to outcome in generalized anxiety disorder (GAD). Psychology and Psychotherapy: Theory, Research and Practice. 81, 247 - 259. DOI:10.1348/147608308X297113

Bowens, M., \& Cooper, M. (2012). Development of a client feedback tool: A qualitative study of therapists' experiences of using the Therapy Personalisation Form. European Journal of Counselling \& Psychotherapy, 14, 47 - 62. DOI:10.1080/13642537.2012.652392

Bowman, L., \& Fine, M. (2000). Client perceptions of couples therapy: Helpful and unhelpful aspects. American Journal of Family Therapy, 28, 295 - 310.

Brocki, J.M., \& Wearden, A.J. (2006). A critical evaluation of the use of interpretative phenomenological analysis (IPA) in health psychology. Psychology \& Health, 21, 87108.

Fischer, C.T. (2009). Bracketing in qualitative research: Conceptual and practical matters. Psychotherapy Research, 19, 583-590.

Handelzalts, J.E., \& Keinan, G. (2010). The effect of choice between test anxiety treatment options on treatment outcomes. Psychotherapy Research. 20(1), 100 - 112. doi:10.1080/10503300903121106

Henkelman, J., \& Paulson, B. (2006). The client as expert: Researching hindering experiences in counselling. Counselling Psychology Quarterly. 19(2), 39 - 150. doi:10.1080/09515070600788303

Humphreys, K., \& Tucker, J.A. (2002). Toward more responsive and effective intervention 
systems for alcohol-related problems. Addiction, 97, 126-132.

Jackson, K.R., Booth, P.G., McGuire, J., \& Salmon, P. (2006). Predictors of starting and remaining in treatment at a specialist alcohol clinic. Journal of Substance Use, 11, 89100

Lindhiem, O., Bennett, C.B., Trentacosta, C.J., \& McLear, C. (2014). Client preferences affect treatment satisfaction, completion, and clinical outcome: A meta-analysis. Clinical Psychology Review, 34, 506-517.

McLeod, J. (2012) What do clients want from therapy? A practice-friendly review of research into client preferences. European Journal of Psychotherapy and Counselling. $14,19-32$.

McLeod, J. (2013). Developing pluralistic practice in counselling and psychotherapy: Using what the client knows. European Journal of Counselling Psychology, 2, 1-14.

McLeod, J. (2015). Client preferences: building bridges between therapy and everyday life. Psychotherapy and Counselling Journal of Australia, 3,2.

Manthei, R.J. (2007). Clients talk about their experience of the process of counselling. Counselling Psychology Quarterly, 20, 1-26. doi:10.1080/09515070701208359

Norcross, J. C., Krebs, P. M., \& Prochaska, J. O. (2011). Stages of change. Journal of Clinical Psychology: In Session, 67, 143-154.

Patterson, C.L., Uhlin, B., \& Anderson, T. (2008). Clients' pretreatment counseling expectations as predictors of the working alliance. Journal of Counseling Psychology. 55(4), 528 - 534. doi:10.1037/a0013289

Prochaska, J. O., \& DiClemente, C. C. (1986). Toward a comprehensive model of change. In W. R. Miller \& N. Heather (Eds.), Treating addictive behaviors: Processes of change. (pp. 2-27). New York: Plenum.

Project MATCH Research Group. (1997). Matching alcoholism treatments to client heterogeneity: Project MATCH posttreatment drinking outcomes. Journal of Studies on Alcohol, 58, 7-29.

Smith, J.A., Flowers, P. \& Larkin, M. (2009). Interpretative Phenomenological Analysis: Theory, Method and Research. London. Sage.

Snape, C., Perren, S., Jones, L., \& Rowland, N. (2003). Counselling - why not? A qualitative study of people's accounts of not taking up counselling appointments. Counselling and Psychotherapy Research, 3, 239 - 245. doi: 10.1080/14733140312331384412

Swift, J.K., \& Callahan, J.L. (2009). The impact of client treatment preferences on outcome: A meta-analysis. Journal of Clinical Psychology, 65, 368 - 381. doi: 0.1002/jclp.20553

Swift, J.K., \& Callahan, J.L. (2010). A comparison of client preference for intervention empirical support versus common therapy variables. Journal of Clinical Psychology, 66, 1217 - 1231. doi: $10.1002 /$ jclp.20720

Swift, J., Callahan, J.L., \& Vollmer, B.M. (2011). Preferences. Journal of Clinical Psychology: In Session, 67, 155 - 165. doi: 0.1002/jclp.20759

Vollmer, B., Grote, J., Lange, R., \& Walker, C. (2009). A therapy preferences interview: Empowering clients by offering choices. Psychotherapy Bulletin, 44, 33 - 37.

Westra, H.A., Aviram, A., Barnes, M., \& Angus, L. (2010). Therapy was not what I expected: A preliminary qualitative analysis of concordance between client expectations and experience of cognitive-behavioural therapy. Psychotherapy Research, 20, 436 446. doi: 10.1080/10503301003657395 
Table 1: Participant information

\begin{tabular}{|c|c|c|c|c|c|c|}
\hline & Age & Gender & Occupation & Ethnicity & $\begin{array}{l}\text { Marital } \\
\text { Status }\end{array}$ & $\begin{array}{l}\text { Previous } \\
\text { Counselling } \\
\text { Experience }\end{array}$ \\
\hline $\begin{array}{l}\text { Participant } \\
1\end{array}$ & 33 & Male & Tradesman & British & Single & $\begin{array}{l}\text { Alcohol } \\
\text { Support } \\
\text { Work }\end{array}$ \\
\hline $\begin{array}{l}\text { Participant } \\
2\end{array}$ & 42 & Female & Manager & British & Married & None \\
\hline $\begin{array}{l}\text { Participant } \\
3\end{array}$ & 35 & Female & $\begin{array}{l}\text { Customer } \\
\text { Assistant }\end{array}$ & British & Separated & $\begin{array}{l}\text { Alcohol } \\
\text { Detox } \\
\text { Support }\end{array}$ \\
\hline $\begin{array}{l}\text { Participant } \\
4\end{array}$ & 58 & Male & Unemployed & British & Divorced & $\begin{array}{l}\text { Previous } \\
\text { XCA } \\
\text { Support }\end{array}$ \\
\hline $\begin{array}{l}\text { Participant } \\
5\end{array}$ & 31 & Male & $\begin{array}{l}\text { Support } \\
\text { Worker }\end{array}$ & British & $\begin{array}{l}\text { Long Term } \\
\text { Relationship }\end{array}$ & $\begin{array}{l}\text { Bereavemen } \\
\mathrm{t} \\
\text { Counselling } \\
\text { and Alcohol } \\
\text { Counselling }\end{array}$ \\
\hline
\end{tabular}


Table 2. Individual patterns of preference

\begin{tabular}{|c|c|c|}
\hline Participant & $\begin{array}{l}\text { What I want to happen in } \\
\text { counselling }\end{array}$ & $\begin{array}{l}\text { What I do not want to happen in } \\
\text { counselling }\end{array}$ \\
\hline 1 & $\begin{array}{l}\text { - therapist to take a lead } \\
\text { - therapist to show their } \\
\text { personality } \\
\text { - focus on what the therapist } \\
\text { thinks is best for me } \\
\text { - therapist to ask questions }\end{array}$ & $\begin{array}{l}\text { - focus on the past } \\
\text { - homework } \\
\text { - to be judged }\end{array}$ \\
\hline 2 & $\begin{array}{l}\text { - using techniques and } \\
\text { exercises } \\
\text { - therapist to show personality } \\
\text { and humour } \\
\text { - some structure } \\
\text { - to be challenging but also to } \\
\text { be gentle } \\
\text { - counsellor to tell me their } \\
\text { thought processes } \\
\text { - homework }\end{array}$ & $\begin{array}{l}\text { - focus on my past } \\
\text { - tough love } \\
\text { - asked lots of questions } \\
\text { - to feel patronised } \\
\text { - be laughed at } \\
\text { - to be dismissed }\end{array}$ \\
\hline 3 & $\begin{array}{l}\text { - given help and advice } \\
\text { - confidentiality } \\
\text { - to be challenged within } \\
\text { reason } \\
\text { - to focus on the past and the } \\
\text { future }\end{array}$ & $\begin{array}{l}\text { - a "softly" approach } \\
\text { - focus on the alcohol use } \\
\text { - becoming dependent on the } \\
\text { counselling } \\
\text { - to be judged } \\
\text { - reading }\end{array}$ \\
\hline 4 & $\begin{array}{l}\text { - given advice } \\
\text { - to be open and honest } \\
\text { - therapist to show personality } \\
\text { and humour } \\
\text { - to not give structure to the } \\
\text { counselling }\end{array}$ & $\begin{array}{l}\text { - reading } \\
\text { - homework } \\
\text { - counsellor to not be } \\
\text { challenging }\end{array}$ \\
\hline 5 & $\begin{array}{l}\text { - to have structure } \\
\text { - to be challenged } \\
\text { - counsellor to use lots } \\
\text { techniques and exercises } \\
\text { - focus on both past and future } \\
\text { - open to advice } \\
\text { - open to homework } \\
\text { - focus on underlying issues } \\
\text { - happy for counsellor to tell } \\
\text { me about themselves }\end{array}$ & $\begin{array}{l}\text { - to not be judged } \\
\text { - not time limited } \\
\text { - lack of focus or goals } \\
\text { - being preached too } \\
\text { - to not be interrupted } \\
\text { - the focus is not on the client / } \\
\text { counsellor relationship }\end{array}$ \\
\hline
\end{tabular}

